\section{Response to: 'New 2019 SLE EULAR/ACR classification criteria are valuable for distinguishing patients with SLE from patients with pSS' by Assan et al}

In addressing the differential classification of systemic lupus erythematosus (SLE) and primary Sjögren's syndrome (pSS), Dr Florence Assan and colleagues ${ }^{1}$ focus on an important and frequently challenging issue.

Distinguishing between SLE and pSS has been a theme from the very beginning of the European League Against Rheumatism/American College of Rheumatology (EULAR/ACR) classification criteria project. For example, the similarities to pSS led to antibodies against Ro/SS-A or La/SS-B being neither of positive nor of negative predictive value for SLE in the early SLE cohort. ${ }^{1}$ In the SLE patient survey, among those who answered this question, $42 \%$ reported anti-Ro and 27\% anti-La positive. ${ }^{2}$

Accordingly, the pSS population was important in testing the SLE classification criteria. Of the non-SLE patients in the combined derivation and validation cohorts, 242 (22\%) had a diagnosis of pSS. ${ }^{34}$ It is therefore not unexpected, but reassuring, to see that Dr Assan and colleagues find a sensitivity of $98 \%$ and a specificity of $96 \%$ for the EULAR/AR criteria when directly tested against a pSS population. ${ }^{5}$

The French group goes one important step further in addressing patients with SLE/pSS overlap situations, which is a group that has not yet been tested with the EULAR/ACR criteria. In their overlap group of 26 patients, they still find 85\% sensitivity for the EULAR/ACR criteria, as compared with $77 \%$ for the Systemic Lupus International Collaborating Clinics (SLICC) and 39\% for the ACR criteria. ${ }^{5}$ This suggests classification of SLE is possible in patients with an overlap syndrome.

Indeed, the possibility to correctly classify SLE in overlap situations was seen as important in EULAR/ACR criteria development. The general attribution rule of the criteria, that items are not scored if there is a more likely cause other than SLE, ${ }^{6}$ was in part devised in response to this idea, which prohibited excluding other diseases, such as pSS. To the best of our knowledge, the study by Drs Assan, Seror, Mariette and Nocturne is the first test of this concept, and we fully agree with them that their study shows the EULAR/ACR criteria to be useful for classification in overlap presentations.

\footnotetext{
Martin Aringer $\odot$, ${ }^{1}$ Karen Costenbader, ${ }^{2}$ Thomas Dörner $(1),{ }^{3}$ Sindhu R Johnson ${ }^{4}$

${ }^{1}$ Division of Rheumatology, Department of Medicine III, University Medical Center and Faculty of Medicine Carl Gustav Carus, TU Dresden, Dresden, Germany
}

${ }^{2}$ Division of Rheumatology and Immunology, Department of Medicine, Brigham and Womens Hospital, Harvard Medical School, Boston, Massachusetts, USA ${ }^{3}$ Department of Rheumatology and Clinical Immunology, Charité Universitätsmedizin Berlin, Corporate member of Freie Universität Berlin, HumboldtUniversität zu Berlin, and Berlin Institute of Health, Berlin, Germany

${ }^{4}$ Division of Rheumatology, Department of Medicine, Toronto Western Hospital, University Health Network, Mount Sinai Hospital, and Institute of Health Policy, Management and Evaluation, University of Toronto, Toronto, Ontario, Canada

Correspondence to Professor Martin Aringer, Internal Medicine III, Medical Faculty, Technical University of Dresden, Dresden D-01307, Germany;

martin.aringer@uniklinikum-dresden.de

Handling editor Josef S Smolen

Competing interests None declared.

Patient consent for publication Not required.

Provenance and peer review Commissioned; internally peer reviewed.

(c) Author(s) (or their employer(s)) 2021. No commercial re-use. See rights and permissions. Published by BMJ.

\section{Check for updates}

To cite Aringer M, Costenbader K, Dörner T, et al. Ann Rheum Dis 2021;80:e123.

Received 10 September 2019

Accepted 10 September 2019

Published Online First 18 September 2019

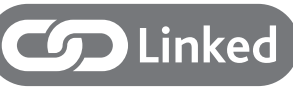

- http://dx.doi.org/10.1136/annrheumdis-2019-216222

Ann Rheum Dis 2021;80:e123. doi:10.1136/annrheumdis-2019-216250

\section{ORCID iDs}

Martin Aringer http://orcid.org/0000-0003-4471-8375

Thomas Dörner http://orcid.org/0000-0002-6478-7725

\section{REFERENCES}

1 Assan F, Seror R, Mariette X, et al. New 2019 SLE EULAR/ACR classification criteria are valuable for distinguishing patients with SLE from patients with pSS. Ann Rheum Dis 2021;80:e122.

2 Mosca M, Costenbader KH, Johnson SR, et al. Brief report: how do patients with newly diagnosed systemic lupus erythematosus present? A multicenter cohort of early systemic lupus erythematosus to inform the development of new classification criteria. Arthritis Rheumatol 2019;71:91-8.

3 Leuchten N, Milke B, Winkler-Rohlfing B, et al. Early symptoms of systemic lupus erythematosus (SLE) recalled by 339 SLE patients. Lupus 2018;27:1431-6.

4 Aringer M, Costenbader K, Daikh D, et al. 2019 European League against Rheumatism/ American College of rheumatology classification criteria for systemic lupus erythematosus. Arthritis Rheumatol 2019;78:1151-9.

5 Aringer M, Costenbader K, Daikh D, et al. 2019 European League against Rheumatism/ American College of rheumatology classification criteria for systemic lupus erythematosus. Arthritis Rheumatol 2019;71:1400-12.

6 Tedeschi SK, Johnson SR, Boumpas D, et al. Developing and refining new candidate criteria for systemic lupus erythematosus classification: an international collaboration. Arthritis Care Res 2018;70:571-81. 